\title{
The Concept of Culture and Higher Education
}

\author{
Peter A. M. Madssen
}

\section{Introduction}

Since the early 1960 s the concept of culture has gradually gained a prominent place in a number of social sciences, like organization theory and management studies, other than its parent discipline, anthropology. Also in studies on higher education the concept of culture has been used to explain, for example, the effectiveness of universities and colleges. However, as with many prominent concepts introduced before in this field (for example, quality, effectiveness and strategy), culture is applied without a clear-cut and undisputed definition, leading to a lot of confusion as well as disagreement on the validity of its use.

It can be argued that there are at least three separate sources for the recent interest of higher education researchers for the concept of culture. First, the early work of Clark $(1970 ; 1972)$ on organizational saga which provided an important, original well-spring for work on culture in higher education. Second, especially in the US, a great deal of the reason for the attention to culture in higher education stems from the ideology of diversity and multiculturalism, and the related negative reactions to logical positivism and quantitative methodology. Third, the growing importance of and interest in institutional management, by some authors referred to as the management revolution in higher education (Rourke and Brooks 1966; Keller 1983), caused a growing interest in the application of the gen- eral work on organizational culture in higher education.

Whatever the source for the increased interest in and use of the concept of culture may be, the scholars applying the concept in the field of higher education have in common that they want to study specific aspects of the non-rational or symbolic side of higher education. As is described by Burton Clark $(1983,72)$

All major social entities have a symbolic side, a culture as well as a social structure, some shared accounts and common beliefs that define for participants who they are, what they are doing, why they are doing it, and whether they have been blessed or cursed.

In this paper I shall refer to the symbolic side of higher education as the academic culture. My definition of academic culture, partly based on the discussion of the relevant literature, will be presented in the final section.

The Initial Use of the Concept of Culture in Higher Education Studies

Initially the interest of higher education researchers in the concept of culture resulted in ethnographic or ethnologic studies of universities and colleges (see, for example: Clark 1960; Trow 1960; Barton 1961; Pace 1962). These scholars wanted to make classifications of higher education institutions by listing various characteristics of these institutions and their environ-

Peter A. M. Meassen is Depury Director of the Center for Higher Education Policy Studies at the Universily of Twente, P.OBox 217, 7500 AE Enschede, the Netherlands. Tel: 3153489 3261. Fax: 3153434 0392. Email: p.a.m.madssen@cheps.utwentenl 
ments. The final listings were identified with college cultures. These authors were especially interested in the impact of institutional cultures on students and they assumed that by asking the right questions they could understand this impact, as is, for example, indicated by Pace (1962, 276):

The fullest advancement of understanding about college cultures and their impact on students will come not only from applying the most rigorous methods, but from using a variety of methods to explore the wisest questions we can formulate.

The so-called College Characteristics Index (CCI), developed by Pace and Stern (1958; see also: Pace 1960, 1962), is an example of an instrument for measuring perceptions of students about their institution. This index consists of 300 statements about college life. Students responding to the statements in the CCI indicate what they perceive as being true and characteristic about their institution. On the basis of these students' responses an institutional profile can be drawn up that can, amongst others, be used for comparisons with other institutions of which students have been asked to respond to the $\mathrm{CCI}$. In addition to the $\mathrm{CCI}$ other methods can be used to look at college environments. The combined use of these methods is expected to give insight in specific aspects of the culture of one or more institutions.

Pace continued his work on measuring the impact of college cultures through the development of the College and University Environment Scales (CUES) and the College Student Experience Questionnaire (CSEQ), both designed to assess specific aspects of the campus environment. Also Clark and Trow's typology of student culture (1966) that, amongst other things, inspired Peterson (1968) to develop his College Student Questionnaire (CSQ) and other instruments, like the Institutional Functioning Inventory (IFI) (Peterson et al. 1970), and the University Residence Environmental Scales (URES) (Moos 1979), have been designed and used to measure specific aspects of student subcultures on campus (for an overview of these and comparable assessment instruments see Baird 1988).

This early approach to studying college culture has more or less faded away in the 1970s (Kuh 1990, 52). A number of reasons can be given for this. First, it was focused at describing the impact of college culture on students. At the beginning of the 1960 students in the US still were a very homogeneous, rather closed, group. It could be assumed that college had a more or less similar impact on each member of this group. Gradually the composition of the student body as well as the nature of student life changed. The riots at the end of the 1960s formed the end of the traditional student life. Student life became more open and the student body was getting very diversified. This implied that it was more and more difficult to measure the impact of college on students, since it could no longer be assumed that the impact would be the same for every student. Also it became impossible to measure the exact impact of college culture in comparison with other influences (Kuh 1990). Second, these early studies were rather descriptive. It was not attempted to explain how college has an impact on students. As a consequence in student oriented studies other perspectives were introduced that could be used to explain college effectiveness. Studies focusing, for example, on student outcomes, trying to analyze the impact of specific classroom interactions on the learning behaviour of students, superseded the early focus on the relationship between college culture and student behaviour. Third, the management revolution of higher education gradually caused a shift in attention of administrators as well as research funding agencies in the US. This shift was followed by researchers. According to Tierney $(1990,1)$ Throughout the 1980 s researchers struggled to define and measure the culture and climate of organizations in order to increase institutional effectiveness'. The emphasis on institutional effectiveness resulted, at least in the US, in studies trying to indicate how institutional effectiveness could be increased through manipulating institutional culture.

This latter development formed the basis for the proposition put forward by Peterson and 
Spencer $(1993,344)$ that 'the concept of organizational culture has been recognized as a critical element in the study of higher education institutions'. This 'critical element' consists, like in organization studies in general, of a focus on the non-rational or symbolic side of organizational life. Hardy $(1990,407)$ argues that 'the research in higher education is far behind the management literature in terms of its understanding of culture'. She even goes so far as to suggest that research on higher education is not well suited for studying culture in a meaningful way, first because it is characterized by a highly atheoretical approach, and second since it is 'predominantly quantitative, functional and objectivistic'. It can be argued that these are characteristics of many higher education studies, especially in the US, but not necessarily of the field of higher education research as such. In the field of higher education particularly, the work of Burton Clark $(1970,1972,1983)$ on organizational saga and the basic types of academic belief is an example of sound and well-founded academic research on understanding culture. Clark's work on organizational saga is even the only literature stemming from the field of higher education referred to regularly in the general organizational literature.

\section{College Cultures in Higher Education}

The literature on the use of the concept of culture in higher education studies can be divided in two parts. The first, and largest, part consists of studies on organizational culture. The second part focuses on disciplinary cultures. Let's start with an overview of the literature on organizational culture in higher education.

One of the few US researchers besides Clark who has tried to build up a cultural framework for analyzing university and college culture is Tierney (1988, 1989, 1990; see also Chaffee and Tierney 1988). However, compared to the work of Clark, Tierney's conceptualizations are rather superficial and anecdotal. For example, his framework of organizational culture (Tierney $1988,8)$ is based on one case study and the author does not explain how it relates to underlying theoretical assumptions with respect to the nature of social science or the nature of society. The 'operative cultural concepts' he introduces to study organizational culture in higher education, that is environment, mission, socialization, information, strategy and leadership, are no operationalizations of cultural concepts, but are claimed to be 'key dimensions of culture' themselves. Tierney $(1988,19)$ suggests that through developing his framework 'administrators will be in a better position to change elements in the institution that are at variance with the culture. This research will permit them to effect orderly change in the organization without creating unnecessary conflict'. Like many other authors, Tierney does not indicate what he sees as the independent and dependent variable(s) in his research efforts. As a result, nowhere in his work does it become clear what it is that he wants to explain.

Other authors who have attempted to conceptualize organizational culture in higher education are, for example, Dill (1982), Masland (1985) and Bergquist (1992). Unlike Clark and Tierney these authors have published only one major article (Dill and Masland) or book (Bergquist) on organizational culture which has its implications for the foundations and applicability of their conceptualizations. Dill $(1982,304)$ points to the neglect of the symbolic side of higher education institutions in discussions of academic management. He suggests that the enterprise culture of universities and colleges is declining in the US. Instead of being oriented towards their institution, academics more and more identify themselves with their individual, disciplinebased, careers. Institutional management is not dealing adequately with this decline, since they are inclined to adopt management techniques of market-based firms. While these techniques may help in the short run, Dill $(1982,319)$ argues that they may do little to increase the productivity, commitment, and loyalty of the professional staff'. The solution to this problem is the development of an appropriate management of academic culture. The emphasis in such a management should be on 'socialization and policies which promote organization-wide communication'. Dill's appeal for more effective aca- 
demic management in higher education institutions is not rooted in specific research findings, nor is it clear on what underlying theoretical notions it is based. His approach contains a number of interesting notions about the symbolic side of higher education institutions. Unfortunately, Dill has not developed his initial conceptualization. As a result his arguments keep floating somewhat in the air.

Masland (1985) examines possible methods, approaches, and techniques for uncovering the influence of organizational culture in higher education. He distinguishes, for example, four 'windows on organizational culture that make it easier to see both past and present cultural influences...saga, heroes, symbols, and rituals' (Masland 1985, 160). The author sees organizational culture as an independent variable in organizational studies in higher education, since in higher education culture can affect student life, administration, and curriculum'. As a result of this central role, organizational culture can act as a form of unobtrusive control, while it is also 'a force that provides stability and a sense of continuity to an ongoing social system such as a college or university' (Masland 1985, 167). Like Dill, Masland has not published any serious continuation to his initial conceptualization. This is a pity, amongst other things, since especially his notion of culture as an unobtrusive form of control would justify further elaboration.

Bergquist (1992) uses definitions of culture from Malinowski (1944), and of organizational culture by Lessem (1990) and Schein (1985), as well as Tierney's work, as the basis for the four cultures of the academy he distinguishes. In explaining these four cultures, that is the collegial culture, the managerial culture, the developmental culture and the negotiating culture, Bergquist hardly indicates what their underlying theoretical assumptions are. Instead he describes their historic origins. For example, the collegial culture is argued to be a hybrid of the British and German university models, while the managerial culture stems from the US Catholic college and university, and the junior or community college. Unfortunately, in presenting how the four cultures manifest themselves in the case studies the author undertook, no relation at all is made to the epistemological roots of the concept of culture, nor to the organizational culture perspectives to which authors like Lessem or Schein belong. Since Bergquist only focuses on perceived manifestations of culture in higher education institutions his four cultures are rather arbitrary. He could, for example, also have distinguished a rational culture or a political culture, instead of, or next to, his four cultures. Like Tierney, Bergquist is a scholar who borrows the concept of culture from anthropology in 'a slanted and biased' (Meek 1988, 454) way. This can be illustrated, for example, by the following quote:

One of the strengths of the developmental culture is its reliance on basic behavioural principles. Although the collegial, managerial, and negotiative cultures tend to offer a mixture of often confusing or even contradictory theories and concepts regarding personal, instructional, and organizational life, the developmental culture provides a clear and coherent theory that can readily be articulated by most members of this culture. Yet this very coherence and uniformity are aiso a source of weakness. It is a culture that attracts a small number of advocates but remains inaccessible to many faculty and administrators who are oriented to one of the other three cultures and who are alienated by the developmentalists' jargon and their pat answers. (Bergquist 1992, 102)

Bergquist not only confuses 'theory' with 'way of life' - see definition of Thompson, Ellis and Wildavsky $(1990,1)$ - but he also misuses organizational culture 'to reify the social reality of organizational life' (Meek 1988, 454).

A number of researchers have studied organizational culture in higher education without having developed or applied an explicit conceptualization of culture. Hardy $(1990,407)$ argues that some of this work has 'fallen into the trap of trivializing the concept of culture'. An example of the latter is Kolman and Hossler's (1987) study on the influence of institutional cultures and sagas on the selection of college presidents. In this study Clark's concept of institutional saga is confused with specific institutional problems like a financial crisis, or conflicts over the mission of 
the college. It is obvious that these problems and conflicts will have a major impact on the selection of a new president, however, they give no indication at all of the existence of an institutional saga or its suggested impact on the search for a new president. Other expressions of a rather trivial use of the concept of culture in higher education can be found in the linking of the term culture to other popular concepts like leadership (McDade and Lewis 1994) without it being explained what is meant by culture and what the relationship looks like.

\section{Disciplinary Cultures in Higher Education}

A number of scholars have tried to explain the functioning of universities and colleges through analyzing the impact of disciplines on specific attitudes, values and behaviours of academics employed by these institutions. Becher (1981, 1989) being one of the few European researchers to have studied culture in higher education focused, for example, exclusively on disciplinary cultures. He argues that 'disciplines are also cultural phenomena: they are embodied in collections of like-minded people, each with their own codes of conduct, sets of values, and distinctive intellectual tasks' (Becher 1981, 109). Interpreting the structure and nature of knowledge within each discipline as core dimensions of differentiation, Becher $(1984,1987)$ has identified four general disciplinary cultures ranging from the hard-pure culture of the sciences, the soft-pure culture of the humanities and the social sciences, to the hard-applied culture of engineering and technology, and the soft-applied cultures of the applied social sciences, like education and social work. His research leads him to suggest that 'an awareness of disciplinary cultures is helpful, and in some cases even essential, to the conduct of research and the development of policy in higher education' (Becher 1994, 159). In trying to explain why in his eyes the characteristic features of disciplines have been generally neglected by higher education researchers, he put forward three competing hypotheses. Firstly, higher education researchers are not naturally conscious of disciplinary issues since higher education re- search is not a discipline in its own right. Secondly, higher education researchers prefer 'keeping to a level of comfortable generality' instead of engaging in hard, painstaking ethnographic studies of disciplines. Thirdly, higher education researchers prefer using rational explanations of academic behaviour instead of more appropriate alternative explanations (Becher 1994, 160). Becher's suggestion that the discipline is the major shaping force of specific attitudes, values and behaviours of academics, is also expressed by other scholars (see, for example, Biglan 1973a, 1973b).

\section{Conclusion}

Both groups of researchers, that is the 'college culture' and the 'disciplinary culture(s)' group, claim to explain specific aspects of the symbolic side of higher education through their interpretation and application of the concept of culture. However, they have limited evidence for their claims since they only looked at the relationship between either the institution or the discipline and academic culture without analyzing any other possible variables that might have an impact. In many of their publications culture is treated as a dependent as well as an independent variable without this being discussed explicitly. It is as if especially the organizational culture proponents want to argue that culture can explain (almost) everything and (almost) anything can be explained by cultural aspects. This position is not limited to scholars belonging to the field of higher education studies. Also in other social sciences, like organization studies (see, for example, Alvesson and Berg 1992), this view on the applicability of the concept of culture can be found.

Consequently the above mentioned work can at best - mainly in the case of the disciplinary culture scholars - be regarded as a first step in unravelling the complex influence of the main (external) sources on the academic culture. For the next steps what is needed, amongst other things, is the awareness that the study of higher education can be divided into two aspects: the substantive activities of academics (working with 
the 'raw material', i.e. knowledge), and the organization of the work of academics, including the attitudes and values of academics towards their work and their profession. The field focusing on the first aspect, 'the science of science' that is studying how knowledge is produced, distributed and applied, has to be distinguished from the field examining the second aspect, higher education studies. My interest lies with the latter, even though I feel that one of the most challenging areas for both fields is studying the interface between the two.

Taking the distinction between the two fields into account I would like to argue that for studying academic culture it is necessary to attempt to analyze in more depth than has been the case so far the factors that influence academic culture. Clark's conceptualizations concerning the external sources that steer academics (Clark 1983, 74-75) can be used as a starting-point for this attempt. He argues that academic belief, that is what I would like to call academic culture, is influenced by the following sources: the discipline, the employing university, the national context and the academic profession at large. Clark argues that there is a lack of serious research on the relationship between these four sources and the functioning of academics. Especially comparisons across countries are so scarce that 'national patterns can only be suggested by examples and illustrations' (Clark 1983, 74). While this quote refers to the beginning of the 1980 s, the situation has not improved much since.

Given my interest and Clark's conceptualizations, I would like to suggest the following definition of academic culture:

Academic culture is the set of attitudes, beliefs, and values that integrates a specific group of academics.

This definition can be used, for example, in studies trying to analyze the impact of governmental policies or steering strategies, disciplinary aspects, the academic profession at large, or the institutional context on the academic culture. The results of such analyses can be used in many ways. It can, for example, lead to a more effective governmental steering strategy with respect to higher education or to a more effective relationship between institutional administration and academic decision makers in universities and colleges. I am afraid that until such research output becomes available we shall be able to observe many invalid and, under certain circumstances, even damaging applications of the concept of culture in higher education.

\section{References}

Alvesson, M. and Berg, P.O. (1992) Corporate Culture and Organizational Symbolism; An Overviciv. Berlin; New York: de Gruyter.

Barton, A.H. (1961) 'Organizational measurement and its bearings on the study of college environments.' Researcb Monograph 2. New York: College Entrance Examination Board.

Baird, L.L. (1988) 'The college environment revisited: a review of research and theory.' In J.C. Smart (ed) Higher Education: Handbook of Theory and Research. Volume $I V$. New York: Agathon Press.

Becher, T. (1981) 'Towards a definition of disciplinary cultures.' Studies in Higher Education 6, 109-122.

Becher, T. (1984) 'The cuitural view.' In B.R. Clark (ed) Perspectives on Higher Education: Eight Disciplinary and Comparative Views. Berkeley: University of California Press.

Becher, T. (1987) "The disciplinary shaping of the profession.' In B.R. Clark (ed) The Academic Profession: National, Disciplinary and Institutional Settings. Berkeley: University of California Press. Becher, T. (1989) Academic Tribes and Territories. Milton Keynes: Open University Press.

Becher, T. (1994) "The significance of disciplinary differences.' Studies in Higber Education 19, 151-161.

Bergquist, W.H. (1992) The Four Cultures of the Academy: Insights and Strategies for Improving Leadersbip in Collegiate Organizations. San Francisco: Jossey-Bass.

Biglan, A. (1973a) "The characteristics of subject matter in different academic areas.' Journal of Applied Psychology 57, 195-203.

Biglan, A. (1973b) 'Relationships between subject matter characteristics and the structure and output of university departments' Journal of Applied Psychology 57, 204-213.

Chaffee, E.E. and W.G. Tiemey (1988) Collegiate Culture and Leadership Strategies. New York: American Council on Education and Macmillan.

Clark, B.R. (1960) The Open Door College New York: McGraw-Hill. 
Clark, B.R. (1970) The Distinctive College: Antioch, Reed and Swarthmore Chicago: Aldine.

Clark, B.R. (1972) "The organizational saga in higher education.' Administratrive Science Quarterby 17, 178-183.

Clark, B.R. (1983) The Higher Education System: Academic Organization in Cross-National Perspective. Berkeley: University of California Press.

Clark, B.R and Trow, M. (1966) 'The organizational context.' In T.M. Newcomb and E.K. Wilson (eds) College Peer Groups: Problems and Prospects for Research. Chicago: Aldine.

Dill, D.D. (1982) 'The management of academic culture: notes on the management of meaning and social integration.' In Higher Education 11, 303-320.

Hardy, C. (1990) 'Putting power into university governance.' In J.C. Smart (ed) Higher Education: Handbook of Theory and Research VI, 393-426. New York: Agathon Press.

Keller, G. (1983) Academic Strategy: The Management Revolution in American Higber Education. Washington, D.C.: American Association for Higher Education.

Kolman, E.M. and Hossler, D. (1987) 'The influence of institutional culture on presidential selection.' The Review of Higher Education 10, 319-333.

Kuh, G.D. (1990) 'Assessing student culture.' In W.G. Tierney (ed) 'Assessing academic climates and cultures.' New Directions for Institutional Research 68, XVII, 4, 47-61. San Francisco: Jossey-Bass.

Lessem, R (1990) Managing Corporate Culture. Brookfield, Vt: Gower.

Malinowski, B. (1944) A Scientific Theory of Culture. Chapel Hill: University of North Carolina Press

Masland, A.T. (1985) 'Organizational culture in the study of higher education.' The Review of Higher Education 8, 157-168.

McDade S.A. and Lewis, P.H. (eds) (1994) 'Developing administrative excellence: creating a culture of leadership.' New Directions for Higher Education 87, XXII, 5-10. San Francisco: Jossey-Bass.

Meek, V.L. (1988) 'Organizational culture: origins and weaknesses.' Organization Studies 9, 4, 453-473.

Moos, RH. (1979) Evaluating Educational Environments. San Francisco: Jossey-Bass.
Pace, C.R. (1960) 'Five college environments.' College Bodrd Review 41, 24-28.

Pace, C.R. (1962) 'Methods of describing college cultures.' Teachers College Record 63, (January) 267-277.

Pace, C.R. and Stern, G.G. (1958) 'An approach to the measurement of psychological characteristics of college environments.' Journal of Educational Psychology 49, 269-277.

Peterson, M.W. and Spencer, M.G. (1993) 'Qualitative and quantitative approaches to academic culture: do they tell us the same thing?' In J.C. Smart (ed) Higher Education: Handbook of Theory and Research LX, 344-388. New York: Agathon Press.

Peterson, R.E. (1968) College Student Questionndire: Technical Manual. Princeton: Educational Testing Service.

Peterson, R.E., Centra, J.A., Hartnett, R.T. and Linn, RL. (1970) Institutional Functioning Inventory: Preliminary Technical Manual. Princeton: Educational Testing Service.

Rourke, F.E. and Brooks, G.E. (1966) The Managerial Revolution in Higher Education. Baltimore: The Johns Hopkins Press.

Schein, E.H. (1985) Organizational Culture and Leadership: A Dynamic View. San Francisco: Jossey-Bass:

Thompson, M., Ellis, R. and Wildavsky, A. (1990) Cultural Theory. Boulder, CO: Westview Press.

Tierney, W.G. (1988) 'Organizational culture in higher education. Defining the essentials.' Journal of Higher Education 59, 2-21.

Tierney, W.G. (1989) 'Symbolism and presidential perceptions of leadership.' The Review of Higher Education 12, 153-166.

Tierney, W.G. (ed) (1990) 'Assessing academic climates and cultures.' New Directions for Institutional Research 68, XVII, 4. San Francisco: Jossey-Bass.

Trow, M. (1960) The Campus Viewed as a Culture: Research on College Students. Boulder: Western Interstate Commission on Higher Education, 105-123. 